\title{
Intraseasonal Variability of the Equatorial Undercurrent in the Indian Ocean $\mathscr{O}$
}

\author{
GENGXIN CHEN \\ State Key Laboratory of Tropical Oceanography, South China Sea Institute of Oceanology, \\ Chinese Academy of Sciences, Guangzhou, China, and Department of Atmospheric and Oceanic Sciences, \\ University of Colorado Boulder, Boulder, Colorado \\ WEIQING HAN \\ Department of Atmospheric and Oceanic Sciences, University of Colorado Boulder, Boulder, Colorado
}

\section{YUANLONG LI}

Key Laboratory of Ocean Circulation and Waves, Institute of Oceanology, Chinese Academy of Sciences, and Function Laboratory for Ocean Dynamics and Climate, Qingdao National Laboratory for Marine Science and Technology, Qingdao, China

\section{JINGLONG YAO AND DONGXIAO WANG}

State Key Laboratory of Tropical Oceanography, South China Sea Institute of Oceanology, Chinese Academy of Sciences, Guangzhou, China

(Manuscript received 23 July 2018, in final form 8 October 2018)

\begin{abstract}
By analyzing in situ observations and conducting a series of ocean general circulation model experiments, this study investigates the physical processes controlling intraseasonal variability (ISV) of the Equatorial Undercurrent (EUC) of the Indian Ocean. ISV of the EUC leads to time-varying water exchanges between the western and eastern equatorial Indian Ocean. For the 2001-14 period, standard deviations of the EUC transport variability are 1.92 and $1.77 \mathrm{~Sv}\left(1 \mathrm{~Sv} \equiv 10^{6} \mathrm{~m}^{3} \mathrm{~s}^{-1}\right)$ in the eastern and western basins, respectively. The ISV of the EUC is predominantly caused by the wind forcing effect of atmospheric intraseasonal oscillations (ISOs) but through dramatically different ocean dynamical processes in the eastern and western basins. The stronger ISV in the eastern basin is dominated by the reflected Rossby waves associated with intraseasonal equatorial zonal wind forcing. It takes 20-30 days to set up an intraseasonal EUC anomaly through the Kelvin and Rossby waves associated with the first and second baroclinic modes. In the western basin, the peak intraseasonal EUC anomaly is generated by the zonal pressure gradient force, which is set up by radiating equatorial Kelvin and Rossby waves induced by the equatorial wind stress. Directly forced and reflected Rossby waves from the eastern basin propagate westward, contributing to intraseasonal zonal current near the surface but having weak impact on the peak ISV of the EUC.
\end{abstract}

\section{Introduction}

In the Indian Ocean, the Equatorial Undercurrent (EUC) is a transient feature driven by seasonally varying surface winds (e.g., Schott and McCreary 2001). The EUC regularly occurs in winter and spring (especially

Supplemental information related to this paper is available at the Journals Online website: https://doi.org/10.1175/JPO-D-180151.s1.

Corresponding author: Dongxiao Wang, dxwang@scsio.ac.cn during February and April) and exists across the equatorial basin (e.g., Knauss and Taft 1964; Reppin et al. 1999). The EUC reappears during summer and fall (e.g., Bruce 1973; Iskandar et al. 2009) but was thought to occur only in both positive Indian Ocean dipole (IOD) and strong Indian monsoon years (Swapna and Krishnan 2008). Combining observational analyses and modeling experiments, Chen et al. (2015a) suggest that the summer-fall EUC tends to occur in the western basin in most years but exhibits evident interannual variability in the eastern basin. They pointed out that different processes dominate the generation of the EUC in the 
western and eastern basins. Reflected Rossby waves from the eastern boundary play a crucial role in the EUC in the eastern basin, whereas directly forced Kelvin and Rossby waves control the EUC in the western basin. The EUC plays an important role in zonal mass and heat and salt transports from the western basin to the east, and it sustains the eastern Indian Ocean upwelling at seasonal and interannual time scales through a buffering process (Chen et al. 2016). Despite these advances in understanding the seasonal and interannual EUC dynamics of the Indian Ocean, a thorough investigation of intraseasonal variability (ISV) of the EUC has not yet been done.

In situ observations of the equatorial currents in the Indian Ocean suggest obvious ISV (e.g., Schott and McCreary 2001), in addition to their seasonal to interannual variability (e.g., Knox 1976; Luyten and Roemmich 1982; Reppin et al. 1999). The dominant spectral peak of intraseasonal zonal currents occurs at 90 days, and there are secondary peaks at 30-60 days (Han et al. 2001; Han 2005). The moored current meter data during April 1979-June 1980 showed a spectral peak of zonal current at 30-60 days at $200 \mathrm{~m}$ in the western equatorial basin (Luyten and Roemmich 1982). In the central basin near the Gan Island, the zonal currents, mixed layer depth, and upperthermocline temperature revealed 30-60-day variability during January 1973-May 1975 (McPhaden 1982). In the eastern basin, the equatorial zonal current $u$ had strong spectral peak at the 30-50-day periods with velocity amplitude of $0.5 \mathrm{~m} \mathrm{~s}^{-1}$ at $40-\mathrm{m}$ depth, as shown by mooring observations at $90^{\circ} \mathrm{E}$ from November 2000 to October 2001 (Masumoto et al. 2005). Significant 30-60-day $u$ variations were also observed in the subsurface layer at $93^{\circ} \mathrm{E}$ during February-December 2000 (Murty et al. 2002).

Wind forcing significantly contributes to the generation of ISV of the equatorial zonal current. McPhaden (1982) suggested that the 30-60-day variability is highly coherent with zonal winds. Based on a continuously stratified ocean model, Moore and McCreary (1990) demonstrated that the observed 40-50-day current variability in the western equatorial Indian Ocean was forced by the 40-50-day wind variability. Based on an ocean general circulation model (OGCM) and a linear continuously stratified ocean model, Han (2005) verified that both the 90- and 30-60-day oscillations are primarily driven by equatorial forcing of atmospheric intraseasonal oscillations (ISOs). As the wind amplitude at the 90-day period is weaker than that for the 30-60-day period, the equatorial Indian Ocean selectively responds to the 90-day winds through the resonant excitation. The spectral peaks of zonal currents at the 30-60-day periods are directly forced by surface winds that peak at 30-60 days and are contributed to by both directly forced and reflected waves in the deeper layers.

Oceanic internal instabilities can also cause intraseasonal variability of the equatorial currents, mainly in the western Indian Ocean. Forced by monthly mean winds, the 40-50-day oscillation still appeared in reduced-gravity ocean models in the western Indian Ocean and was thought to be generated by instabilities associated with the East African Coastal Current (Kindle and Thompson 1989; Woodberry et al. 1989). Sengupta et al. (2001) forced an OGCM with daily wind stress and obtained 30-50-day fluctuations in the western equatorial region and in the central basin around Sri Lanka. They concluded that oceanic instabilities play an important role in causing these fluctuations.

While the EUC has been shown to exhibit obvious seasonal and interannual variability and ISV of the equatorial Indian Ocean has been extensively studied, a comprehensive study that focuses on ISV of the EUC has not yet been reported. In particular, the importance of wind forcing and oceanic internal instability in generating the variability of the EUC at intraseasonal time scales has not been assessed. Characteristics and generation mechanisms of the intraseasonal EUC variability at different longitudes require in-depth investigation. The goal of this research is to characterize and explain the ISV of the EUC in the Indian Ocean. Our results show that the ISV of the EUC is predominantly forced by winds associated with atmospheric ISOs, but through different dynamical processes in the eastern and western basins. The stronger ISV in the eastern basin is dominated by the reflected Rossby waves, whereas the peak intraseasonal EUC anomaly in the western basin is generated by the eastward pressure gradient force, which is set up primarily by Rossby waves driven by the western basin easterly and oceanic eddies. We verify that the oceanic instabilities contribute to the ISV in the western basin, as suggested by previous studies. However, even in the western basin, oceanic instabilities also have smaller contributions to the EUC ISV than wind.

The rest of the paper is organized as follows. Section 2 describes data and OGCM experiments performed for our analysis. Section 3 presents the results of our analysis, with section 3 a verifying the model performance, section $3 \mathrm{~b}$ investigating the features of the EUC variability in the western and eastern basins, and section $3 \mathrm{c}$ exploring dynamics of the intraseasonal EUC. Section 4 provides a summary and discussion.

\section{Data and ocean models}

\section{a. Data and methods}

Current measurements from two equatorial moorings of the Research Moored Array for African-AsianAustralian Monsoon Analysis and Prediction (RAMA; 
see McPhaden et al. 2009) are used to document the ISV of equatorial currents and to validate the OGCM performance. One mooring is deployed at $0^{\circ}, 90^{\circ} \mathrm{E}$ and provides data from 14 November 2000 to 7 June 2012 at depths ranging from 40 to $410 \mathrm{~m}$. The other is deployed at $0^{\circ}, 80.5^{\circ} \mathrm{E}$ and provides data from 27 October 2004 to 17 August 2012 at depths from 25 to $350 \mathrm{~m}$. Daily data from these moorings are used for our analysis. To reveal the propagation and evolution of atmospheric ISOs, satellite-observed $1^{\circ} \times 1^{\circ}$, daily outgoing longwave radiation (OLR) data (Liebmann and Smith 1996) and $0.25^{\circ} \times 0.25^{\circ}$, daily cross-calibrated (CCMP) satellite ocean surface wind vectors (Atlas et al. 2008) are also analyzed.

Following Chen et al. (2015a, 2016), the EUC is defined as an eastward zonal flow in the equatorial Indian Ocean, with its core located in the thermocline at $60-160 \mathrm{~m}$ and beneath a westward or weaker eastward-flowing surface current, and it lasts for at least 1 month. To better reflect the EUC strength, we calculate the EUC mean velocity and transport between $\sigma_{\theta}=23.5$ and $25.5 \mathrm{~kg} \mathrm{~m}^{-3}$ in the vertical direction and $2^{\circ} \mathrm{S}-2^{\circ} \mathrm{N}$ in the meridional direction. The isopycnals $\sigma_{\theta}=23.5$ and $25.5 \mathrm{~kg} \mathrm{~m}^{-3}$ are chosen because they encompass the depths of the EUC and central thermocline and exclude the effect of the surface Wyrtki jets [see Chen et al. (2016) for details]. Unless otherwise specified, EUC mean velocity and transport are based on this definition.

\section{b. OGCM and experiments}

The OGCM used in this study is the Hybrid Coordinate Ocean Model (HYCOM; e.g., Wallcraft et al. 2009) version 2.2.18, which is configured to the Indian Ocean Basin $\left(30^{\circ}-122.5^{\circ} \mathrm{E}, 50^{\circ} \mathrm{S}-30^{\circ} \mathrm{N}\right)$ with a horizontal resolution of $0.25^{\circ} \times 0.25^{\circ}$ and 26 vertical layers ( $\mathrm{Li}$ et al. 2014, 2015). The surface atmospheric forcing fields include $10-\mathrm{m}$ winds from the CCMP version 1.1 product, the $0.25^{\circ} \times 0.25^{\circ}$ Advanced Scatterometer (ASCAT) satellite ocean surface vector winds, $1^{\circ} \times 1^{\circ}$ surface net shortwave radiation (SWR) and longwave radiation (LWR) from the Clouds and the Earth's Radiant Energy System (CERES; Wielicki et al. 1996), $0.25^{\circ} \times 0.25^{\circ}$ precipitation from the Tropical Rainfall Measuring Mission (TRMM) Multisatellite Precipitation Analysis (TMPA) level 3B42 V7 product (Kummerow et al. 1998), and the $0.75^{\circ} 2-\mathrm{m}$ air temperature and humidity from the ECMWF interim reanalysis (Dee et al. 2011). Detailed information about the model configuration and forcing fields can be found in Li et al. (2014).

The model is spun up from a state of rest for 30 years using monthly climatological forcing. Then, HYCOM was integrated forward by CCMP winds from 1 March 2000 to 31 December 2010 and by ASCAT winds from
1 January 2011 to 31 December 2014, with all other forcing fields from the datasets described above for the entire period of 2000-14. This experiment is named as the main run (MR). To isolate the effects of individual processes, two additional experiments were performed. To entirely exclude the forcing by atmospheric ISOs, in the NoISO experiment, all of the atmospheric forcing fields are low-pass filtered with a 105-day Lanczos digital filter. Intraseasonal variability in NoISO thus estimates the impact of oceanic internal variability (i.e., internal instabilities), whereas the difference between MR and NoISO (i.e., MR - NoISO) measures the overall forcing effect of atmospheric ISOs on the ocean. The third experiment, NoSTRESS, has only 105-day low-passfiltered wind stress. As we will see later, zonal currents along the equator from MR - NoSTRESS agree well with those of MR - NoISO, suggesting that the impact of atmospheric ISOs on EUC is mainly through intraseasonal wind stress forcing. Output of the four experiments is all stored as 3-day mean data, and the 14-yr records of 2001-14 are used for our analysis. All observational and model data are bandpass filtered with a 30-105-day Lanczos digital filter to obtain their intraseasonal components. We also examined the sensitivity of the filtered results to the selection of different cutoff periods of 30-90, 30-100, and 30-105 days and obtained similar results (not shown). Given that ocean response to intraseasonal wind forcing has larger amplitude at lower frequency and obtains a peak response near the 90-day period (Han et al. 2001; Han 2005), we choose the 30-105-day periods to fully contain the oceanic intraseasonal signals.

\section{Results}

To investigate ISV of the EUC, all current, SSH, OLR, and wind stress anomalies we show below are the 30-105-day-filtered intraseasonal components.

\section{a. Model/data comparison}

Earlier studies have shown that HYCOM is able to well represent the upper-ocean processes in the tropical Indian Ocean, including sea surface temperature (e.g., Li et al. 2013, 2014, 2017), sea surface salinity (Li et al. 2015), and sea surface height (SSH; Chen et al. 2015b). HYCOM is also successful in simulating seasonal and interannual variabilities of equatorial currents by comparing with RAMA observations and the ECMWF Ocean Reanalysis System, version 4 (ORAS4) data (Chen et al. 2015b). In addition, HYCOM captures ISV of equatorial currents in the upper ocean (Chen et al. 2017). The correlation coefficients between the nearsurface intraseasonal zonal flow from RAMA moorings 

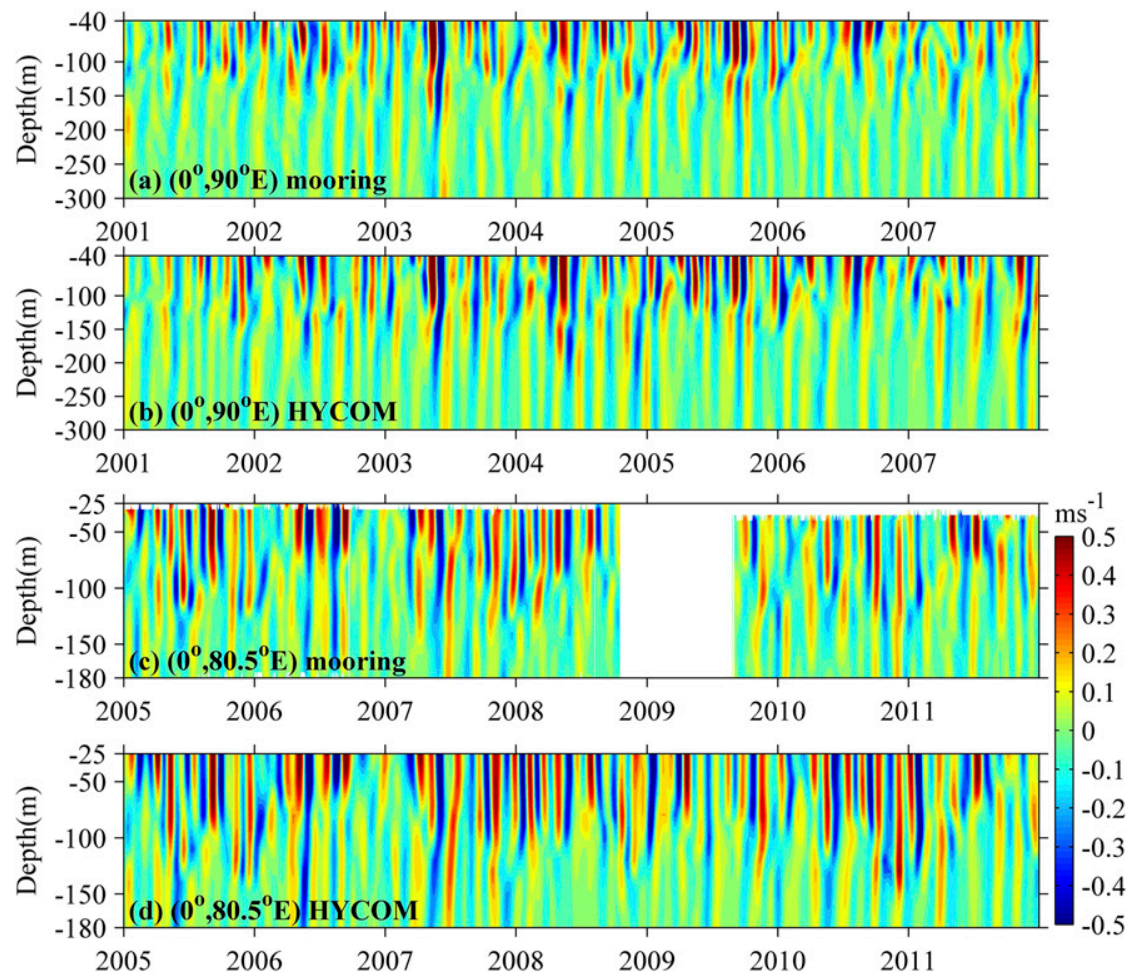

FIG. 1. (a) RAMA mooring-observed intraseasonal (30-105-day bandpass filtered) zonal current $u\left(\mathrm{~m} \mathrm{~s}^{-1}\right)$ of $40-300 \mathrm{~m}$ at $0^{\circ}, 90^{\circ} \mathrm{E}$ from 2001 to 2007. (b) As in (a), but from HYCOM MR. (c),(d) As in (a) and (b), but for $25-180 \mathrm{~m}$ at $0^{\circ}, 80.5^{\circ} \mathrm{E}$ from 2005 to 2011.

and from $\mathrm{HYCOM} \mathrm{MR}$ at $0^{\circ}, 90^{\circ} \mathrm{E}$ and $0^{\circ}, 80.5^{\circ} \mathrm{E}$ reach 0.86 and 0.84 , and standard deviations (STDs) from RAMA and HYCOM are similar with values of 0.10 versus $0.12 \mathrm{~m} \mathrm{~s}^{-1}$ and 0.11 versus $0.13 \mathrm{~m} \mathrm{~s}^{-1}$ at the two mooring locations, respectively (see Fig. 3 of Chen et al. 2017).

Herein, we further compare the amplitude and phase of the intraseasonal zonal velocity anomaly at $0^{\circ}, 90^{\circ} \mathrm{E}$ and $0^{\circ}, 80.5^{\circ} \mathrm{E}$ from $\mathrm{HYCOM}$ with those from RAMA moorings. Figure 1 shows that HYCOM has faithfully captured both the phases and amplitudes of observed ISV of $u$ velocity, verifying the high correlation and similar STDs with the RAMA moorings, as suggested by Chen et al. (2017). Note that Fig. 1 shows results from only 7 years, in order to clearly display and compare the observed and simulated variations. Comparisons for the entire 2001-14 period yield similar results (not shown). The STDs of intraseasonal $u$ velocity in the thermocline at $60-160 \mathrm{~m}$ at $0^{\circ}, 90^{\circ} \mathrm{E}$ and $0^{\circ}, 80.5^{\circ} \mathrm{E}$ are approximately $91 \%$ and $74 \%$ of the STDs of their seasonal cycles for the 2001-14 period in HYCOM MR. Given the strong seasonal variation due to monsoon wind forcing, the high percentages indicate large amplitudes of ISV.

The intraseasonal $u$ anomalies are strong near the surface (Fig. 1) and are determined primarily by the first and second baroclinic modes (Han et al. 1999; Nagura and McPhaden 2010). At the depths of the thermocline, however, intraseasonal $u$ anomalies also have large amplitudes in some years with clear upward phase propagation, implying the combined effects of multimodes because a sole mode has no vertical energy propagation. To test the hypothesis, vertical normal mode decomposition (Shankar et al. 1996; Ren et al. 2018 ) is performed with the climatologic density profile at $0^{\circ}, 90^{\circ} \mathrm{E}$ of World Ocean Atlas 2013 (WOA13). At each time step, the intraseasonal $u$ anomalies at $0^{\circ}, 90^{\circ} \mathrm{E}$ in observations are projected onto each normalized vertical normal mode. The two leading vertical normal modes (mode 1 plus mode 2; Fig. 2b) have captured both the phases and amplitudes of observed ISV of $u$ velocity. The discrepancies (Fig. 2c) between the original anomaly (Fig. 2a) and the first two modes (Fig. 2b) mainly appear at the depths of the thermocline. Even so, the STDs of intraseasonal $u$ from the first two modes in the thermocline at $60-160 \mathrm{~m}$ are still approximately $46 \%$ and $24 \%$ of that from the original anomaly. The discrepancies in the thermocline are attributed to contributions of other modes. Chen et al. (2015a) concluded that currents in the thermocline can be represented by the sum of the first eight modes, and the intermediate 


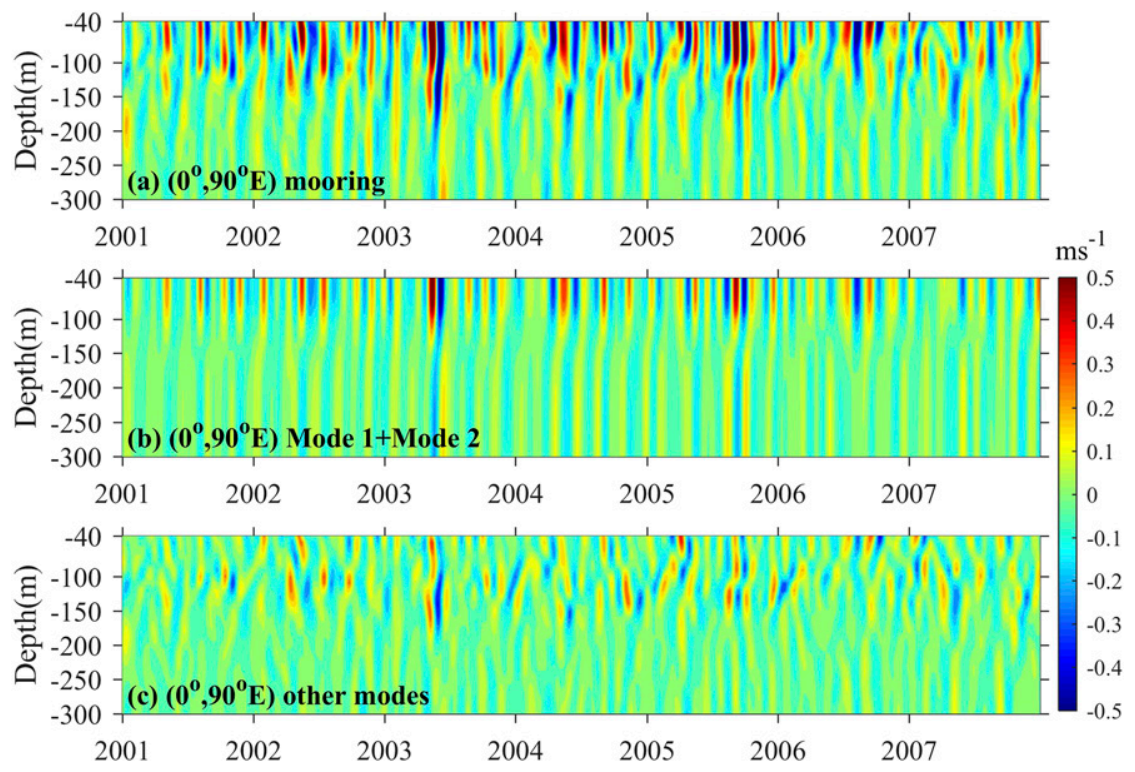

FIG. 2. (a) As in Fig. 1a. (b) Intraseasonal $u$ anomalies projected onto the first two baroclinic modes (mode 1 plus mode 2). (c) The discrepancy between (a) and (b).

modes 3-8 are equatorial waves with significant damping and are important for the EUC.

\section{b. ISV of the EUC in the eastern and western basins}

To reveal an overall distribution of the intraseasonal EUC magnitude, Fig. 3a shows the STD map of intraseasonal $u$ anomalies averaged over $60-160 \mathrm{~m}$ from HYCOM MR during 2001-14. Evidently, large-amplitude
ISVs occur in the equatorial Indian Ocean, especially in the eastern basin and near the western boundary. In the eastern basin, the large STD of intraseasonal $u$ anomalies $\left(>0.1 \mathrm{~m} \mathrm{~s}^{-1}\right)$ coincides with the large STD of intraseasonal zonal wind stress anomalies $\left(>0.03 \mathrm{Nm}^{-2}\right.$; Fig. 3b), implying the important role of intraseasonal wind stress in causing intraseasonal $u$ anomalies at the subsurface layer. In contrast, the strong ISV of $u$ at the western boundary

(a) STD of intraseasonal $u$ anomalies

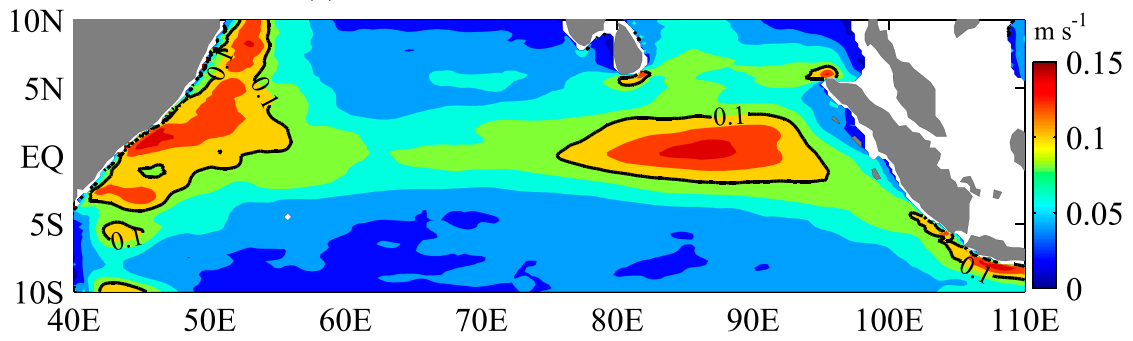

(b) STD of intraseasonal zonal wind stress anomalies

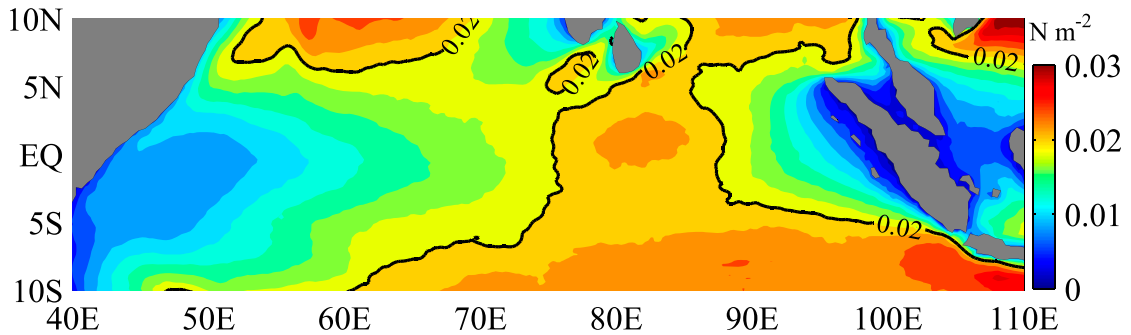

FIG. 3. The STD maps of (a) intraseasonal $u$ anomalies averaged at $60-160 \mathrm{~m}$ from HYCOM MR and (b) intraseasonal zonal wind stress anomalies from CCMP during 2001-14. The black lines in (a) and (b) represent $0.1 \mathrm{~m} \mathrm{~s}^{-1}$ and $0.02 \mathrm{~N} \mathrm{~m}^{-2}$, respectively. 

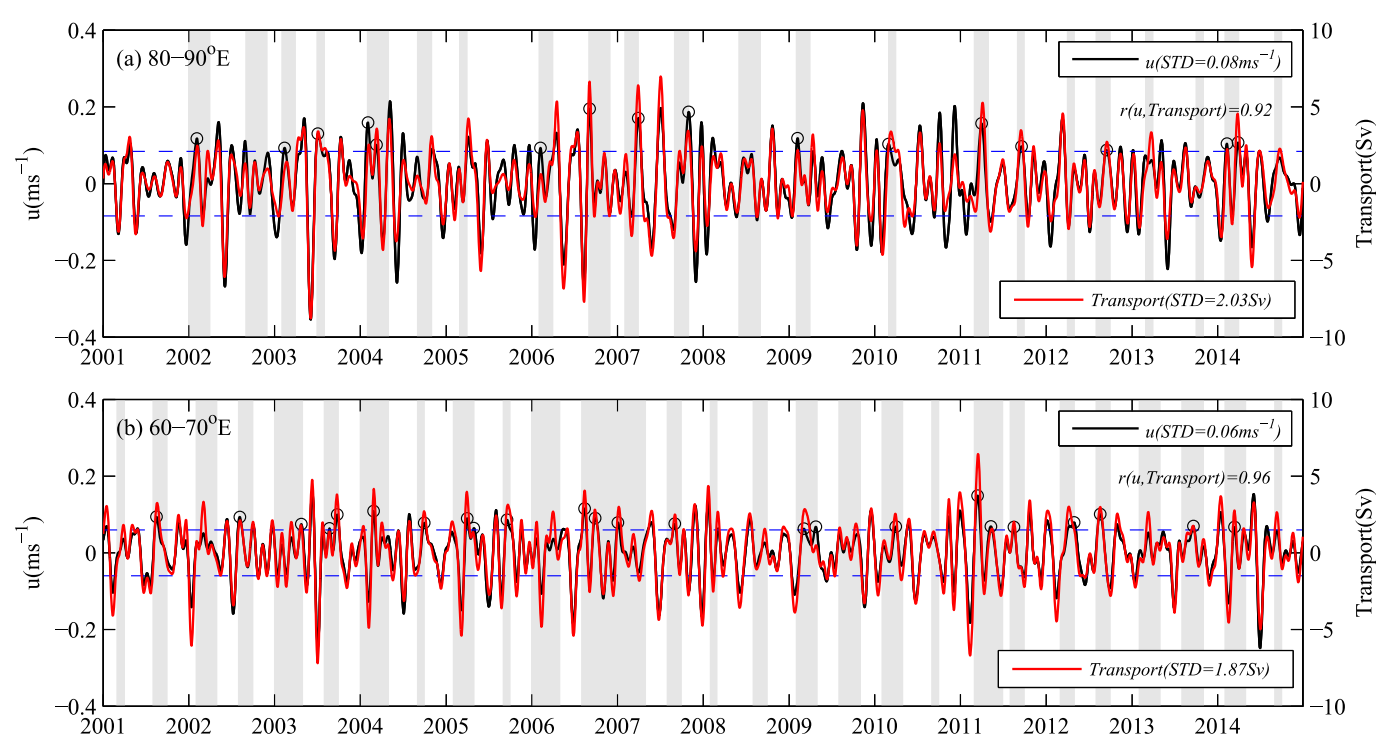

FIG. 4. (a) Intraseasonal $u$ (black line) and $u$ transport (red line) anomalies averaged for $80^{\circ}-90^{\circ} \mathrm{E}, 2^{\circ} \mathrm{S}-2^{\circ} \mathrm{N}$ and 23.5-25.5 $\mathrm{kg} \mathrm{m}^{-3}$ from HYCOM MR. The $23.5-25.5 \mathrm{~kg} \mathrm{~m}^{-3}$ density range spans the seasonal EUC core region (Chen et al. 2015a). The shaded areas show the EUC appearance, and the dashed blue horizontal lines show \pm 1 STDs of the $u$ anomaly. Circles mark the $u$ maxima related to EUC ISV with magnitudes exceeding +1 STD. (b) As in (a), but for $u$ and $u$ transport averaged at $60^{\circ}-70^{\circ} \mathrm{E}, 2^{\circ} \mathrm{S}-2^{\circ} \mathrm{N}$ and $23.5-25.5 \mathrm{~kg} \mathrm{~m}^{-3}$.

corresponds to weak ISV of local zonal wind stress, indicating that local forcing may not be crucial, and oceanic instabilities, together with remote forcing, may play a dominant role there (see section 1). Note that the EUC in the western basin is located off the western boundary (Chen et al. 2016), where its ISV is weaker than that in the eastern basin (Fig. 3a).

Given that large EUC variability occurs in the eastern basin and, to a lesser degree, western basin (interior), we focus on investigating the ISV of the EUC in these two basins. Zonal averages of $u$ for $60^{\circ}-70^{\circ} \mathrm{E}$ and $80^{\circ}-90^{\circ} \mathrm{E}$ from HYCOM MR are chosen to illustrate the EUC in eastern and western basins, respectively. The gray bars, representing the EUC existence identified based on monthly HYCOM MR outputs (see section 2a), appear more frequently in the western basin (cf. Figs. 3a and 3b), verifying the conclusion of Chen et al. (2015a) that the EUC tends to occur in the western basin but exhibits obvious interannual variability in the eastern basin.

The volume transport and intensity of the western basin EUC are computed by integrating and averaging the $80^{\circ}-90^{\circ} \mathrm{E}$ mean $u$ over the $\sigma_{\theta}=23.5-25.5 \mathrm{~kg} \mathrm{~m}^{-3}$ and $2^{\circ} \mathrm{S}-2^{\circ} \mathrm{N}$ area, respectively (black and red lines in Fig. 4). The STDs of intraseasonal velocity and transport anomalies in the central thermocline reach $0.08 \mathrm{~m} \mathrm{~s}^{-1}$ and $2.03 \mathrm{~Sv}$ $\left(1 \mathrm{~Sv} \equiv 10^{6} \mathrm{~m}^{3} \mathrm{~s}^{-1}\right)$, respectively, which are comparable to the seasonal transport variation of the EUC (STD $=3.60 \mathrm{~Sv}$; Chen et al. 2015a). Intraseasonal intensity is highly correlated with intraseasonal transport, with a correlation coefficient of 0.92 , implying that the thickness of the central thermocline has weak intraseasonal variations. Compared to the eastern basin, the subsurface current in the western basin shows weaker ISV. STDs of intensity and transport in the western basin are $0.06 \mathrm{~m} \mathrm{~s}^{-1}$ and $1.87 \mathrm{~Sv}$, respectively. Note that the ISVs of zonal velocity and transport shown in Fig. 4 are for the entire 2001-14 period, but only the years marked by the gray bars reflect the EUC ISV. We thus further calculate STDs of velocity and transport of the EUC ISV for the EUC years, and the values are $0.08 \mathrm{~m} \mathrm{~s}^{-1}$ and $1.92 \mathrm{~Sv}$ in the western basin and $0.05 \mathrm{~m} \mathrm{~s}^{-1}$ and $1.77 \mathrm{~Sv}$ in the eastern basin, respectively. As the velocity is also highly correlated with the transport in the western basin (Fig. 4b), we omit the transport and only show the velocity to explore ISV of the EUC in the central thermocline in the following text.

\section{c. Causes for ISV of the EUC}

\section{1) WIND STRESS FORCING VERSUS OCEANIC INTERNAL VARIABILITY}

HYCOM experiments are analyzed to understand the underlying physical processes of generation of the EUC ISV. The intraseasonal $u$ anomaly in the eastern basin from MR - NoISO, measuring the overall forcing effect of atmospheric ISOs on the ocean, agrees quite well with that in MR, showing a linear correlation coefficient of 0.89 (above $95 \%$ significance; cf. black and red lines in Fig. 5a). The STD of intraseasonal velocity anomaly in 

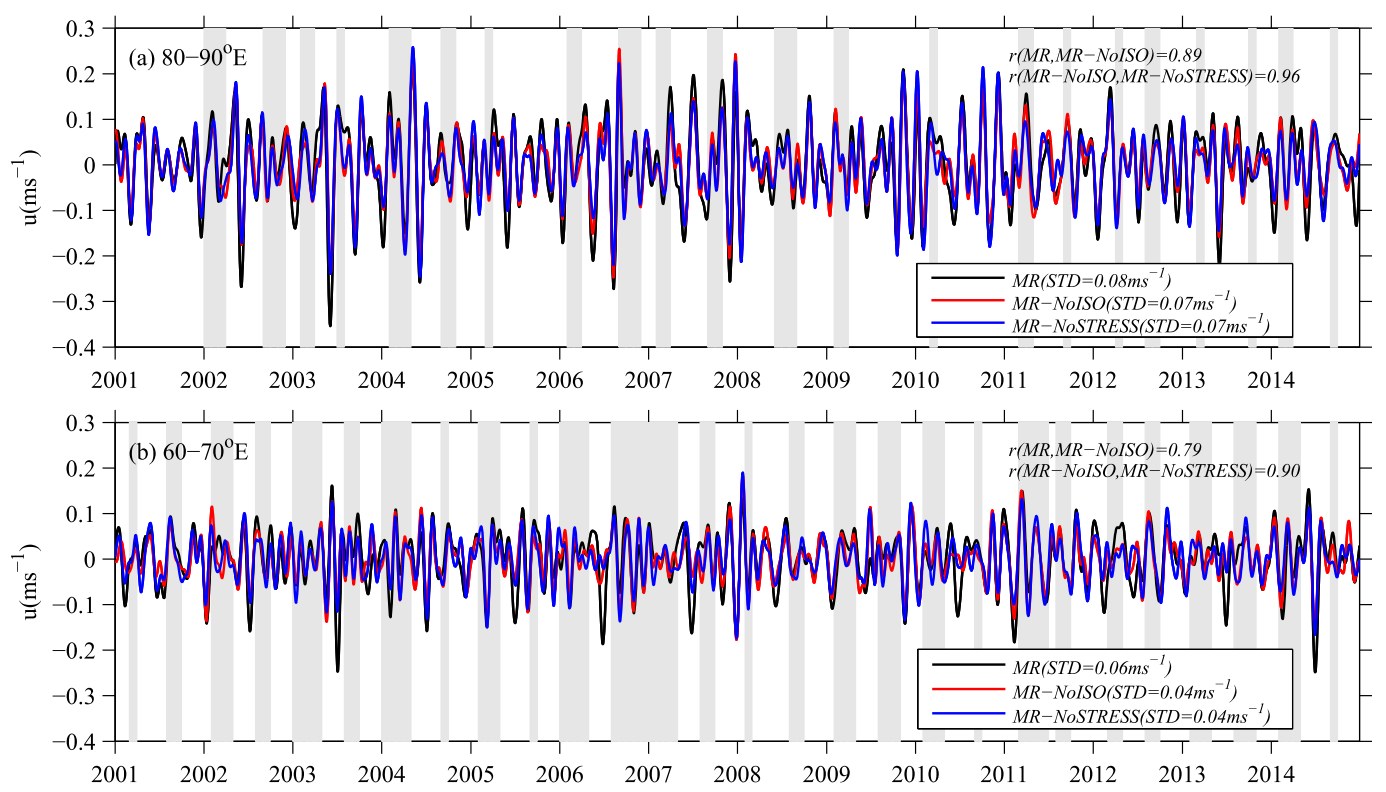

FIG. 5. (a) Intraseasonal $u$ anomaly averaged at $80^{\circ}-90^{\circ} \mathrm{E}, 2^{\circ} \mathrm{S}-2^{\circ} \mathrm{N}$ and $23.5-25.5 \mathrm{~kg} \mathrm{~m}^{-3}$ from the MR, MR NoISO (red line), and MR - NoSTRESS (blue line). (b) As in (a), but for $u$ averaged at $60^{\circ}-70^{\circ} \mathrm{E}, 2^{\circ} \mathrm{S}-2^{\circ} \mathrm{N}$ and $23.5-25.5 \mathrm{~kg} \mathrm{~m}^{-3}$.

MR - NoISO is $0.07 \mathrm{~m} \mathrm{~s}^{-1}$, which is also close to that in MR $\left(0.08 \mathrm{~m} \mathrm{~s}^{-1}\right)$. The good agreement between MR and MR - NoISO suggests that the ISV of $u$ is predominantly forced by atmospheric ISOs rather than induced by oceanic internal instabilities. By excluding intraseasonal wind stress forcing in the NoSTRESS experiment, we further find that the effect of atmospheric ISOs on the ocean current anomaly is mainly through intraseasonal wind stress forcing (cf. red and blue lines in Fig. 5a), which affects the current ISV through ocean dynamical processes rather than through surface buoyancy fluxes (heat and freshwater fluxes). The current ISV induced by surface wind stress (MR - NoSTRESS) has the same STD magnitude $\left(0.07 \mathrm{~m} \mathrm{~s}^{-1}\right)$ as that induced by total ISO forcing, and their correlation coefficient reaches 0.96 .

Different from the eastern basin, oceanic internal variability (i.e., instabilities) contributes substantially to ISV of $u$ in the western basin (Fig. 5b), as suggested by previous studies (e.g., McPhaden 1982; Han 2005; Sengupta et al. 2001). The STD of the velocity anomaly in the MR - NoISO is $0.04 \mathrm{~m} \mathrm{~s}^{-1}$, compared to $0.06 \mathrm{~m} \mathrm{~s}^{-1}$ in the MR, accounting for only $\sim 67 \%$ of the MR STD in the western basin $(\sim 89 \%$ for the eastern basin). The composite analysis clearly shows eddy-like structures in the western basin, verifying the importance of oceanic instabilities there [see section 3c(3)]. However, even in the western basin, oceanic instabilities also have a smaller contribution to the EUC ISV than wind (cf. black and red lines in the shaded area of Fig. 5b). When only the EUC-occurrence period is considered, the STD of the $u$ anomaly in MR - NoISO is $\sim 97 \%$ of the MR STD, and the correlation coefficient between MR - NoISO and MR during the EUC period reaches 0.85 , compared to 0.79 during the entire period. These results suggest that atmospheric ISOs, rather than oceanic instabilities, dominate ISV of the EUC in the western basin. Similar to the situation in the eastern basin, the effect of atmospheric ISOs on $u$ anomaly is mainly through intraseasonal wind stress forcing (cf. red and blue lines in Fig. 5b).

\section{2) Processes: EAstern BASIN}

To further explore the effects of wind stress on the ISV of $u$, we perform lagged correlation analyses between the CCMP intraseasonal zonal wind stress anomaly at each grid point and the subsurface zonal velocity averaged for the eastern equatorial basin $\left(80^{\circ}-\right.$ $90^{\circ} \mathrm{E}$ ) from HYCOM MR shown in Fig. 3a, when wind leads velocities by $30,25,20,10,5$, and 0 days (left column in Fig. 6). The results demonstrate that intraseasonal $u$ of the thermocline in the eastern basin is significantly affected by zonal wind stress in the central and eastern equatorial regions. While the negative correlation exceeds -0.4 from $60^{\circ}$ to $95^{\circ} \mathrm{E}$ along the equator when wind stress leads by 30 days, the positive correlation exceeds +0.4 from $60^{\circ}$ to $80^{\circ} \mathrm{E}$ when wind stress leads by 5 days. This is because both eastern-boundary 

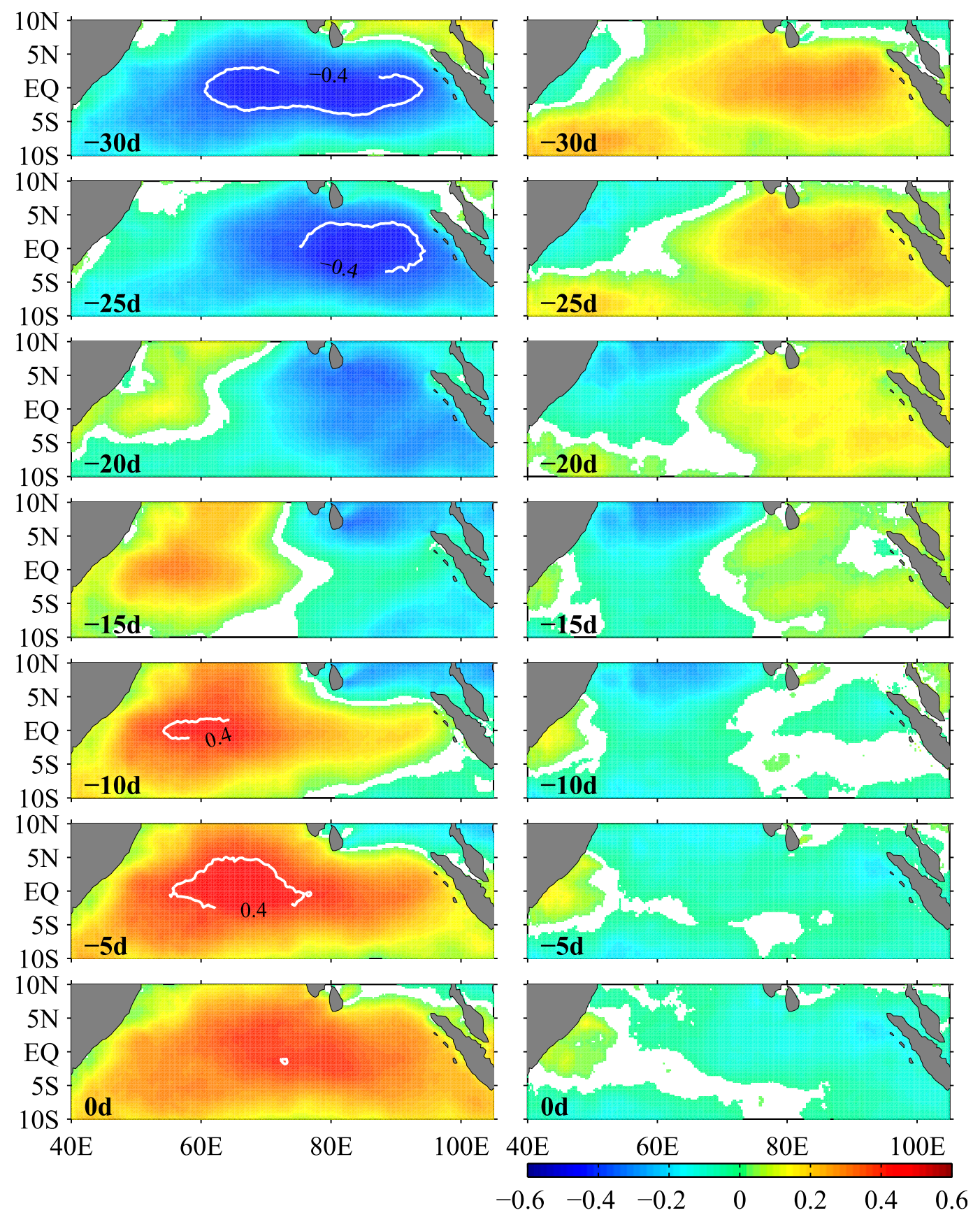

FIG. 6. (left) Correlation coefficients between intraseasonal CCMP zonal wind stress $\tau^{x}$ at each grid point and the intraseasonal $u$ anomaly averaged at $80^{\circ}-90^{\circ} \mathrm{E}, 2^{\circ} \mathrm{S}-2^{\circ} \mathrm{N}$ and $23.5-25.5 \mathrm{~kg} \mathrm{~m}^{-3}$ from the MR when $\tau^{x}$ leads SSHA by $30,25,20,15,10,5$, and 0 days. The white contours represent \pm 0.4 correlations. Correlation values below the $95 \%$ significance level are masked white. (right) As in the left column, but for the correlations between $\tau^{x}$ and the intraseasonal $u$ anomaly averaged at $60^{\circ}-70^{\circ} \mathrm{E}, 2^{\circ} \mathrm{S}-2^{\circ} \mathrm{N}$ and $23.5-25.5 \mathrm{~kg} \mathrm{~m}^{-3}$.

reflected Rossby waves and directly forced Kelvin waves contribute to the EUC ISV in the eastern basin, as further elaborated below.

To illustrate the processes that control the EUC ISV, we perform composite analyses for the strong ISV events of the EUC. The \pm 1 STDs of intraseasonal zonal velocities in the thermocline from the MR (Fig. 3a) are used to identify strong EUC ISV events. Based on these criteria, we identify 17 positive and 6 negative EUC ISV events in the eastern basin, with positive ISV events 

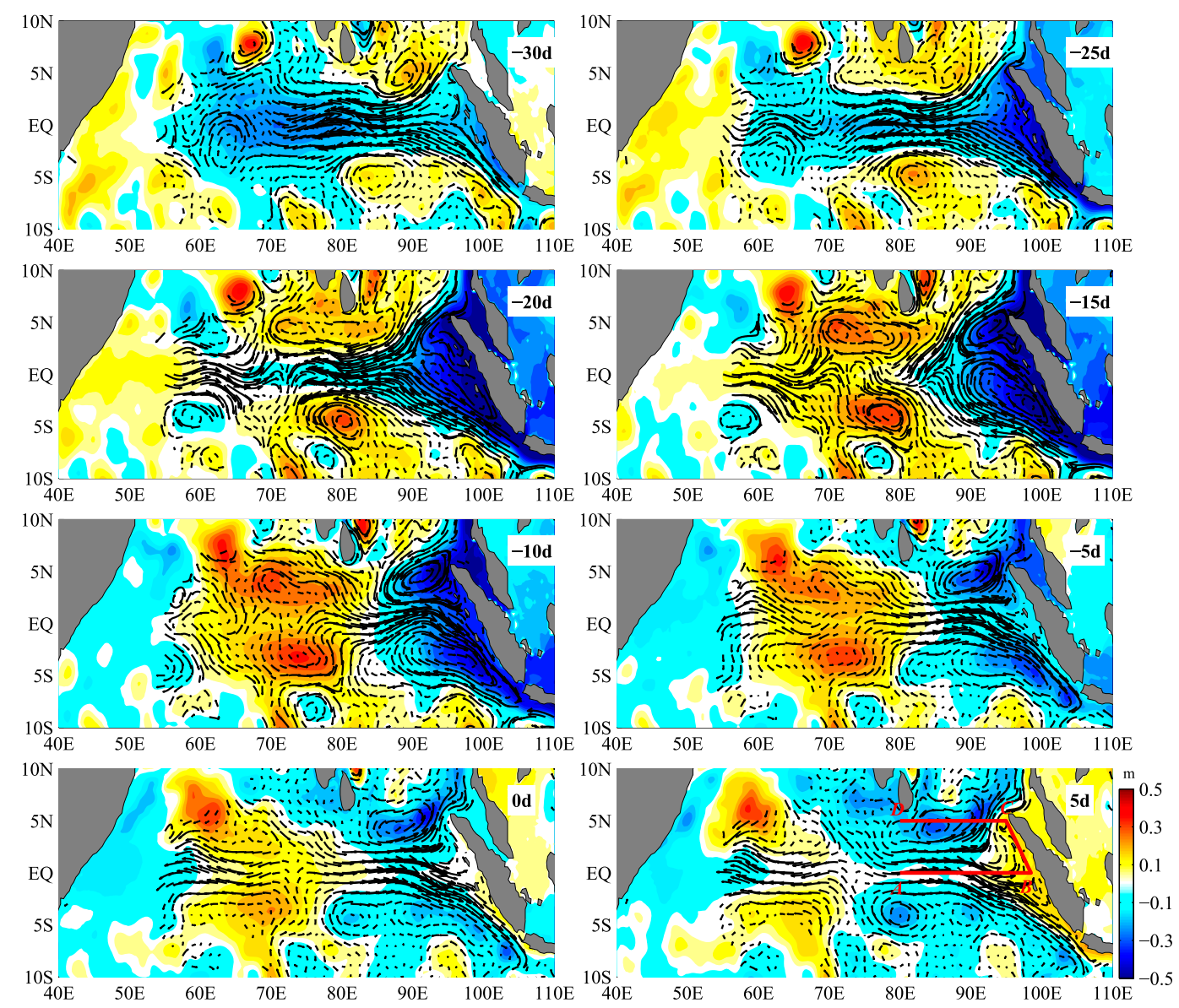

FIG. 7. Composite intraseasonal current anomaly averaged at $23.5-25.5 \mathrm{~kg} \mathrm{~m}^{-3}$ (vectors) and SSHA of the strong $u$ events in the eastern basin (marked by circles in Fig. 4a). The red lines in the last subplot denote routes along the equator (A-B), along the coasts of Sumatra (B-C), and along $5^{\circ} \mathrm{N}(\mathrm{C}-\mathrm{D})$. Longitudes of A-D are $80^{\circ}, 98.5^{\circ}, 95^{\circ}$, and $80^{\circ} \mathrm{E}$, respectively. The isopycnal $\sigma_{\theta}=23.5 \mathrm{~kg} \mathrm{~m}^{-3}$ is ventilated near the western boundary region, and thus vectors are missing there.

representing strengthened seasonal EUC and negative events representing weakened seasonal EUC. Because of their similar evolutions, here, we only show the composite results of positive ISV events labeled by circles in Fig. 4a. The days with maxima of intraseasonal EUC anomaly are taken as day 0 . Then, current composites at the subsurface layer averaged between $\sigma_{\theta}=$ 23.5 and $25.5 \mathrm{~kg} \mathrm{~m}^{-3}$ and intraseasonal SSH anomaly (SSHA) for 30 days before (day -30 ) and 5 days after $($ day +5$)$ day 0 are obtained (Fig. 7). To help understand the processes that generate the EUC ISV, we also obtain the corresponding composites of intraseasonal OLR anomaly (OLRA) and wind stress anomalies (Fig. 8), surface and thermocline zonal currents together with zonal wind stress along the equator $\left(2^{\circ} \mathrm{S}-2^{\circ} \mathrm{N}\right.$ average; Fig. 9), SSHA along the route of equatorial Kelvin and reflected Rossby waves (Fig. 10), and longitude-depth sections of $u$ along the equator (Fig. 11).
Surface wind anomalies diverge from the weakened convection (positive OLRA) regions, forming anomalous easterly wind anomalies in the eastern equatorial basin (Fig. 8a). The equatorial easterly wind anomalies (Fig. 8a and contour in Fig. 9a; -30 day) induce equatorial Ekman divergence and off-equatorial Ekman convergence, causing negative SSHA and westward currents along the equator but positive SSHA and associated anticyclonic circulations on both sides of the equator (vectors in Fig. 7 and color in Fig. 9a). The negative SSHA signals propagate eastward along the equator as equatorial Kelvin waves, enhancing their amplitude toward the east and attaining the maximum near the eastern boundary (days $-30,-25$, and -20 of Fig. 7). Meanwhile, the positive SSHAs on both sides of the equator, a typical structure of the first meridional mode Rossby wave, propagate westward. 
(a) the eastern basin
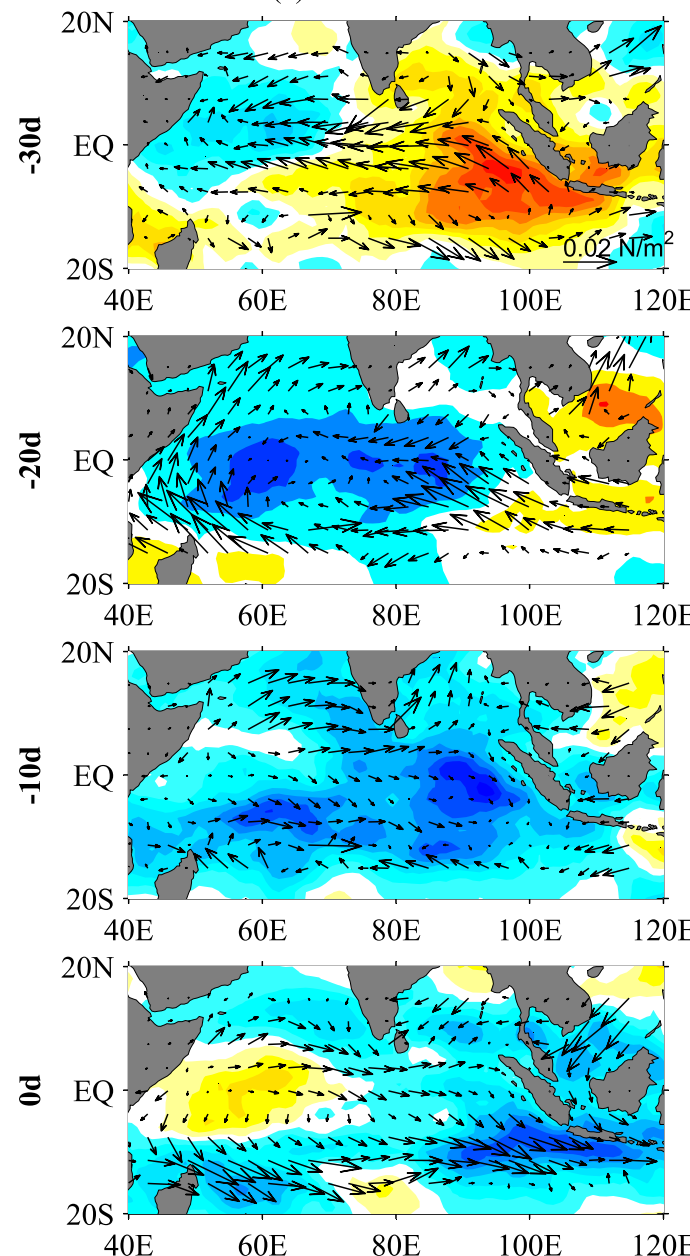

(b) the western basin
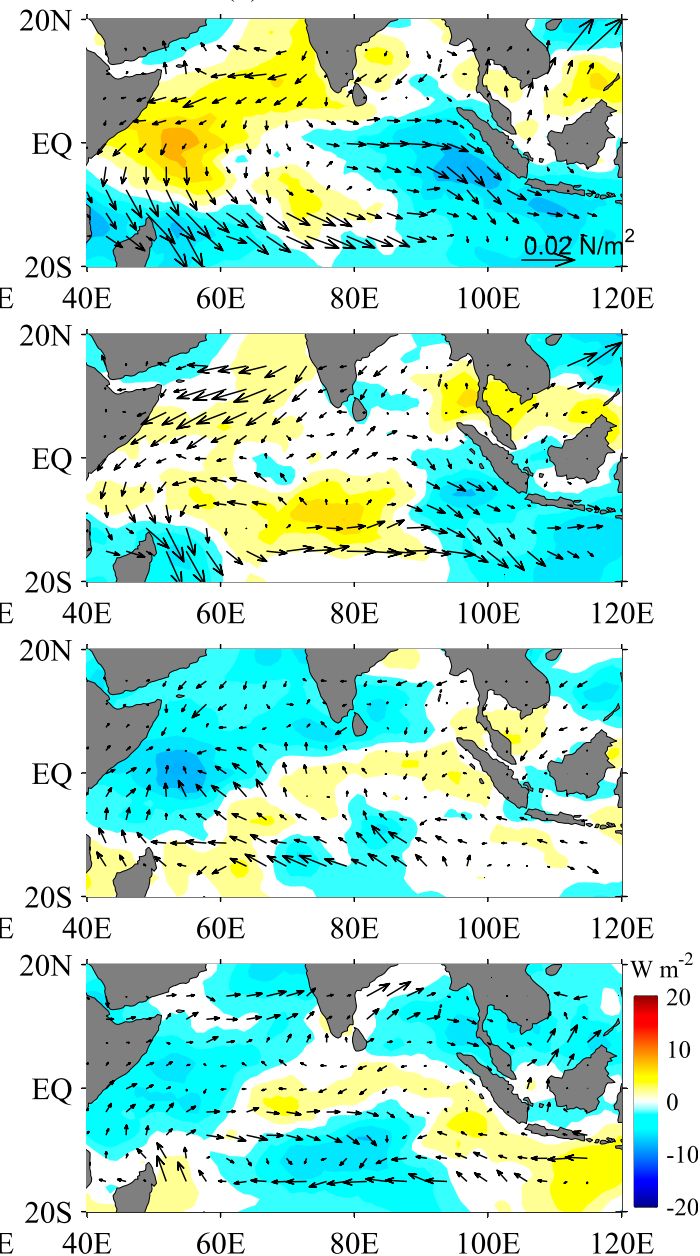

FIG. 8. Composite intraseasonal OLR anomaly (color; $\mathrm{W} \mathrm{m}^{-2}$ ) and intraseasonal wind stress anomaly (vectors; $\mathrm{N} \mathrm{m}^{-2}$ ) in the tropical Indian Ocean corresponding to the strong $u$ events (marked by circles in Fig. 4) in (a) the eastern basin and (b) the western basin.

Upon the Kelvin wave arriving at the eastern boundary, the negative SSHA signals radiate westward as long Rossby waves, with cyclonic eddy-like structures centered at $5^{\circ} \mathrm{N}$ and $5^{\circ} \mathrm{S}$ because of symmetric equatorial Rossby waves (from day -20 to day 5 of Fig. 7; Chen et al. 2017). The time-distance plots of intraseasonal SSHA along route A-B-C-D (red line in bottom-right panel of Fig. 7) from HYCOM MR clearly show the forced Kelvin waves with faster speed and the reflected Rossby waves with slower speed (Fig. 10a). It takes about 1 month from $\mathrm{A}$ to $\mathrm{D}$ because of a mixed behavior of the first and second baroclinic modes (Chen et al. 2017). The reflected Rossby waves are associated with eastward currents in the eastern equatorial basin, which offset the westward flow associated with equatorial Kelvin waves in order to satisfy the no-normal-flow $(u=0)$ condition at the eastern continental boundary of the equatorial Indian Ocean. Evidently, the eastward $u$ of the reflected Rossby waves contributes significantly to the EUC (days $-10,-5$, and 0 of Fig. 7). These reflected Rossby waves explain the negative correlation with a 30-day lead of zonal wind stress in the middle-eastern equatorial Indian Ocean (top-left panel in Fig. 6).

Starting from approximately day -10 , intraseasonal wind stress anomalies change from westward to weakly eastward (Fig. 8a and contours in Fig. 9a), as zonal wind stress has a primary spectral peak at 30-60 days along the equator (Han 2005). The weakening of easterlies and appearance of weak westerlies relax the east-towest pressure gradient that was set up after the propagation of Kelvin and Rossby waves, and the eastward pressure gradient force causes an eastward intraseasonal EUC. In addition, the westerly wind anomalies force equatorial Ekman convergence and induce positive 

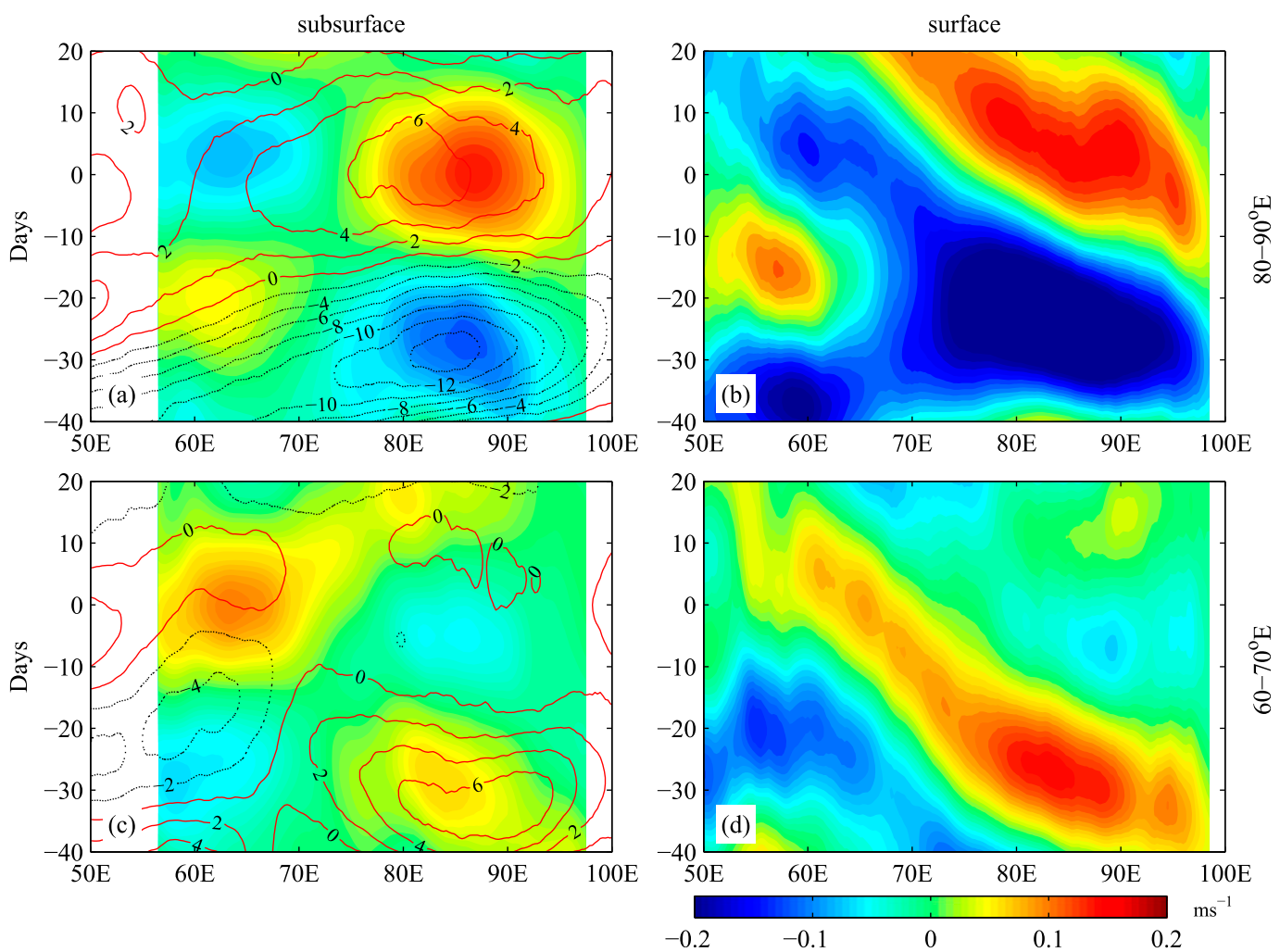

FIG. 9. (a) Composite intraseasonal $u$ anomaly averaged at $2^{\circ} \mathrm{S}-2^{\circ} \mathrm{N}, 23.5-25.5 \mathrm{~kg} \mathrm{~m}^{-3}$ (color; $\mathrm{m} \mathrm{s}^{-1}$ ) and intraseasonal zonal wind stress anomaly averaged at $2^{\circ} \mathrm{S}-2^{\circ} \mathrm{N}$ (contour; $\times 10^{-3} \mathrm{~N} \mathrm{~m}^{-2}$ ) of the strong $u$ events in the eastern basin (marked by circles in Fig. 4a). Negative values mean westward. (b) Composite intraseasonal $u$ anomaly at surface layer averaged at $2^{\circ} \mathrm{S}-2^{\circ} \mathrm{N}$ for the strong $u$ events. (c) As in (a), but for the strong $u$ events in the western basin (marked by circles in Fig. 4b). (d) As in (b), but for the strong $u$ events in the western basin.

SSHA and eastward currents in the upper ocean (Figs. 7, 9a, and 11). These directly forced eastward currents explain the positive correlation with a $5 \sim 10$-day lead of zonal wind stress in the central equatorial basin (left column in Fig. 6). Although we cannot cleanly isolate the effects of reflected and directly forced waves, the clear contribution of eastward thermocline flow associated with reflected Rossby waves suggests their important roles in causing ISV of the eastern basin EUC.

The composite $u$ sections along the equator further support our discussion (Fig. 11). The westward currents associated with the easterly wind anomalies occupy the eastern equatorial basin with the largest velocity at the surface, and the current signals penetrate down way below $100 \mathrm{~m}$ in the eastern basin, which is much deeper than the penetration at seasonal and interannual time scales shown by Chen et al. (2015a). This is because the angles of Kelvin and Rossby wave rays are proportional to their frequencies: the higher the frequency, the steeper the ray angle and the deeper the downward penetration (e.g., Han 2005). The negative equatorial $u$ anomalies propagate westward as Rossby waves (Figs. 7 and 11). On day -15 , when the structures of reflected Rossby waves clearly appear in the eastern basin (Fig. 7), the eastward current appears at the EUC depth and intensifies until day 0 , causing intraseasonal enhancement of the EUC (from day -10 to 0 of Fig. 11). The eastward currents exhibit obvious baroclinic structures because the reflected Rossby waves are mainly composed of the first and second baroclinic modes (Han 2005; Chen et al. 2017).

It takes 20-30 days to set up the positive EUC ISV events (Figs. 7, 9, and 11), switching from westward to eastward on the equator. Since it takes another 20-30 days to recover the westward current (figure not shown), the EUC ISV in the eastern basin originates mainly from the current anomalies on 30-60-day periods, which is the secondary spectral peak over the intraseasonal frequency range and forced by wind stress associated with atmospheric ISOs. The larger variances of currents at 90 days, arisen mainly from resonant excitation, should contribute less to the EUC ISV in the eastern basin, as it shifts westward to the western basin at the subsurface layer (Han 2005). 

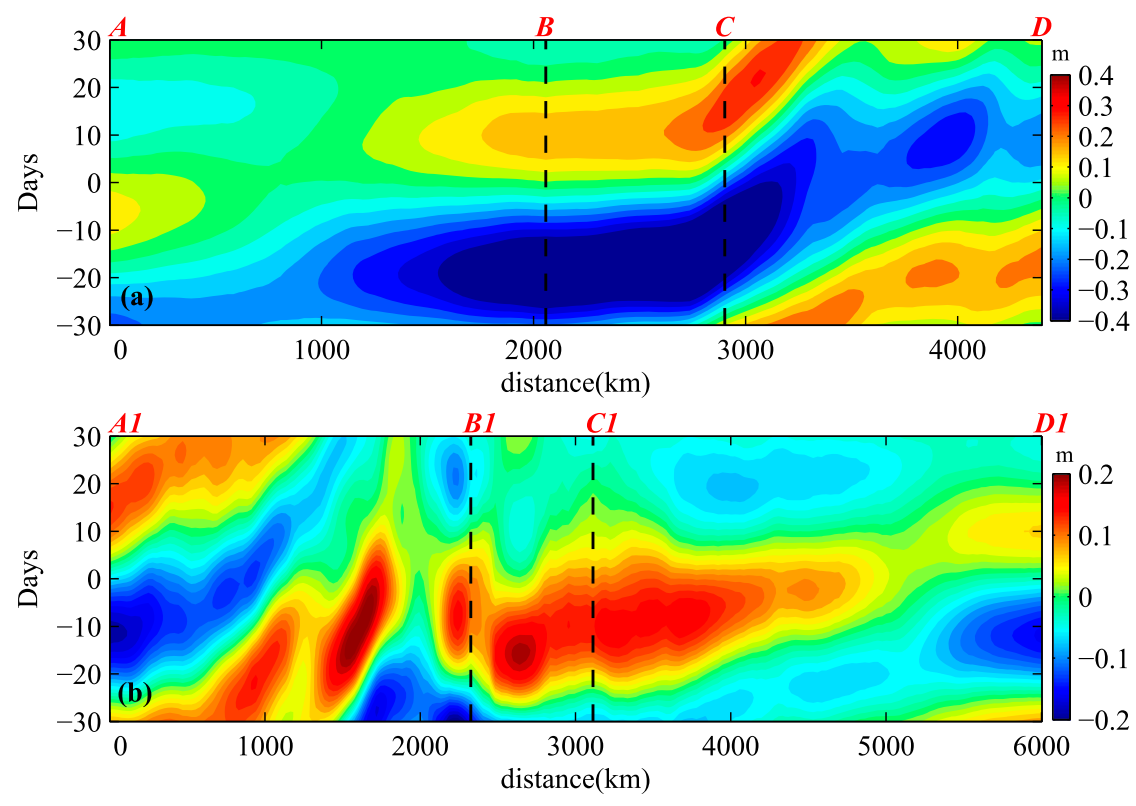

FIG. 10. (a) Composite time-distance plots of intraseasonal SSHA from HYCOM MR along route A-B-C-D shown in Fig. 7. (b) As in (a), but along route A1-B1-C1-D1 shown in Fig. 12.

\section{3) Processes: Western BAsin}

The weaker correlation between CCMP intraseasonal wind stress and intraseasonal EUC of the western basin (right column in Fig. 6) implies that not only intraseasonal wind stress, but also oceanic instabilities, contribute to ISV of the western basin EUC. Based on the 23 positive EUC ISV events labeled by circles in Fig. $4 \mathrm{~b}$, we perform composite analyses to illustrate the processes for the wind stress to induce the EUC ISV in the western basin. Note that $\sigma_{\theta}=23.5 \mathrm{~kg} \mathrm{~m}^{-3}$ is ventilated near the western boundary region because of the shallower depth of the mean thermocline there, compared to the east; we thus adopt a current averaged at $60-160 \mathrm{~m}$ instead of $23.5-25.5 \mathrm{~kg} \mathrm{~m}^{-3}$ to quantify the EUC variability (Fig. 12). The composite current from the fixed depth presents a similar pattern to that from isopycnals (figure not shown) but with larger horizontal coverage, and it is suitable for our investigation.

On day -30 and day -20 , the surface wind stress converges to (diverges from) the negative (positive) OLRA in the eastern (western) basin, causing equatorial westerly wind anomalies in the eastern basin and easterly wind anomalies in the western basin (Figs. 8b and 9c). The easterly wind anomaly drives westward currents in the western equatorial basin, and the westerly wind anomaly forces eastward currents in the eastern equatorial basin (Figs. 12 and 13). The structures of the first meridional mode Rossby waves forced by the easterly (westerly) wind in the western (eastern) basin are clear in Fig. 12 and are associated with equatorial westward current and off-equatorial anticyclonic circulations (positive SSHA) in the western basin, but eastward equatorial current and off-equatorial cyclonic circulations (negative SSHA) in the eastern basin. The Rossby waves propagate westward, becoming unstable and forming eddies near $55^{\circ} \mathrm{E}$, which intensify from day -30 to -15 . Meanwhile, two eddies with positive SSHA occupy the western boundary region of the equatorial basin and also enhance from day -30 to day -15 (Fig. 12). The positive SSHAs from the Rossby waves forced by the western basin easterly wind merge with those of western boundary eddies on day -10 , forming positive SSHA in the western basin (days -5 and 0). The high SSHAs in the western basin, together with the low SSHAs associated with Rossby waves, produce a strong eastward pressure gradient force along the equator, driving the eastward ISV of the EUC in the western basin (from day -10 to day 0 of Fig. 12; Fig. 13). The eastward pressure gradient force associated with directly forced Rossby waves drives intraseasonal zonal current in the equatorial Indian Ocean and has been suggested by Senan et al. (2003) and Sengupta et al. (2007). The peak ISV (day 0) of the western basin EUC appears to have little contribution from Rossby waves generated in the eastern basin - both the directly forced Rossby waves by westerly winds (positive $u$ at $80^{\circ}-90^{\circ} \mathrm{E}$ in Fig. 9c) and the reflected Rossby waves at the eastern boundary (negative $u$ in Fig. 12)—although these waves 

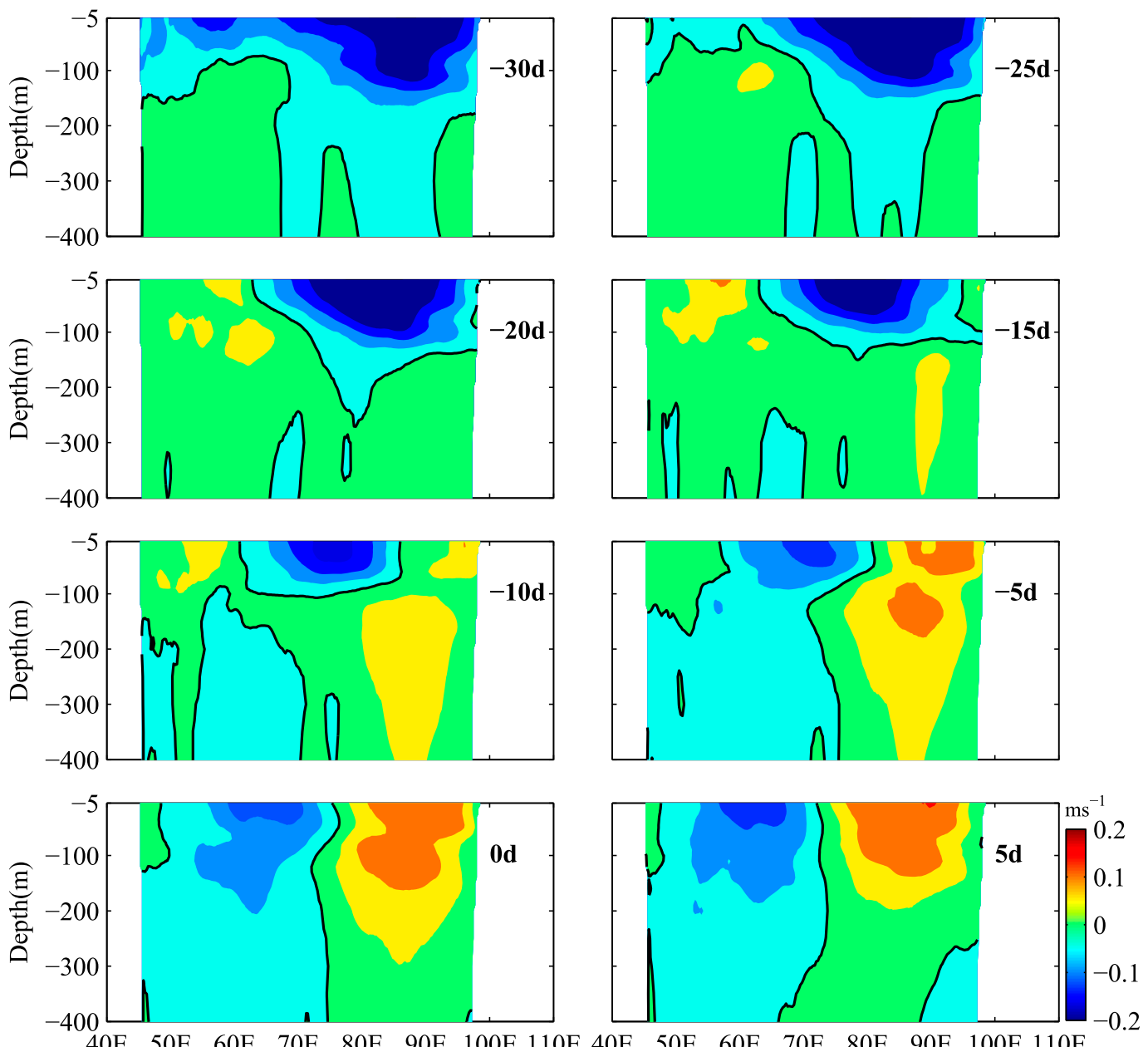

FIG. 11. Composite intraseasonal $u$ anomaly section averaged at $2^{\circ} \mathrm{S}-2^{\circ} \mathrm{N}$ of the strong $u$ events in the eastern basin (marked by circles in Fig. 4a).

contribute significantly to the western basin intraseasonal current at the surface (Fig. 9d) and to the Somali Current near the equator (Shinoda et al. 2017).

As discussed above, the intraseasonal SSHAs associated with the Rossby waves become chaotic before reaching the western boundary (Figs. 10b and 12), owing to the strong influence of ocean internal instability. This complication makes it difficult to discern the effect of western boundary reflection. Previous studies demonstrate that the reflection efficiency at the western boundary is much lower than that at the eastern boundary, and current variability in the interior of the Indian Ocean is relatively insensitive to western boundary reflections (e.g., Nyadjro and McPhaden 2014; Chen et al. 2015a). These results suggest that the reflection at the western boundary may have less contribution on the EUC ISV, different from the situation at the eastern boundary (Fig. 10).

\section{Summary and discussion}

The EUC is a transient feature in the equatorial Indian Ocean that regularly occurs over the whole equatorial basin during winter-spring and reappears mainly in the western basin but exhibits obvious interannual variability in the eastern basin during summerfall (Chen et al. 2015a). In this paper, we combine observational analyses using RAMA mooring and modeling experiments using HYCOM to investigate intraseasonal variability of the EUC, which has not yet been systematically investigated before. Since the EUC in the western and eastern basins originates from different control factors and exhibits obvious time and space differences, we choose zonal-averaged velocities between $\sigma_{\theta}=23.5$ and $25.5 \mathrm{~kg} \mathrm{~m}^{-3}$ at $60^{\circ}-70^{\circ} \mathrm{E}$ and $80^{\circ}-90^{\circ} \mathrm{E}$ to illustrate the EUC variation in eastern and western basins, respectively. 

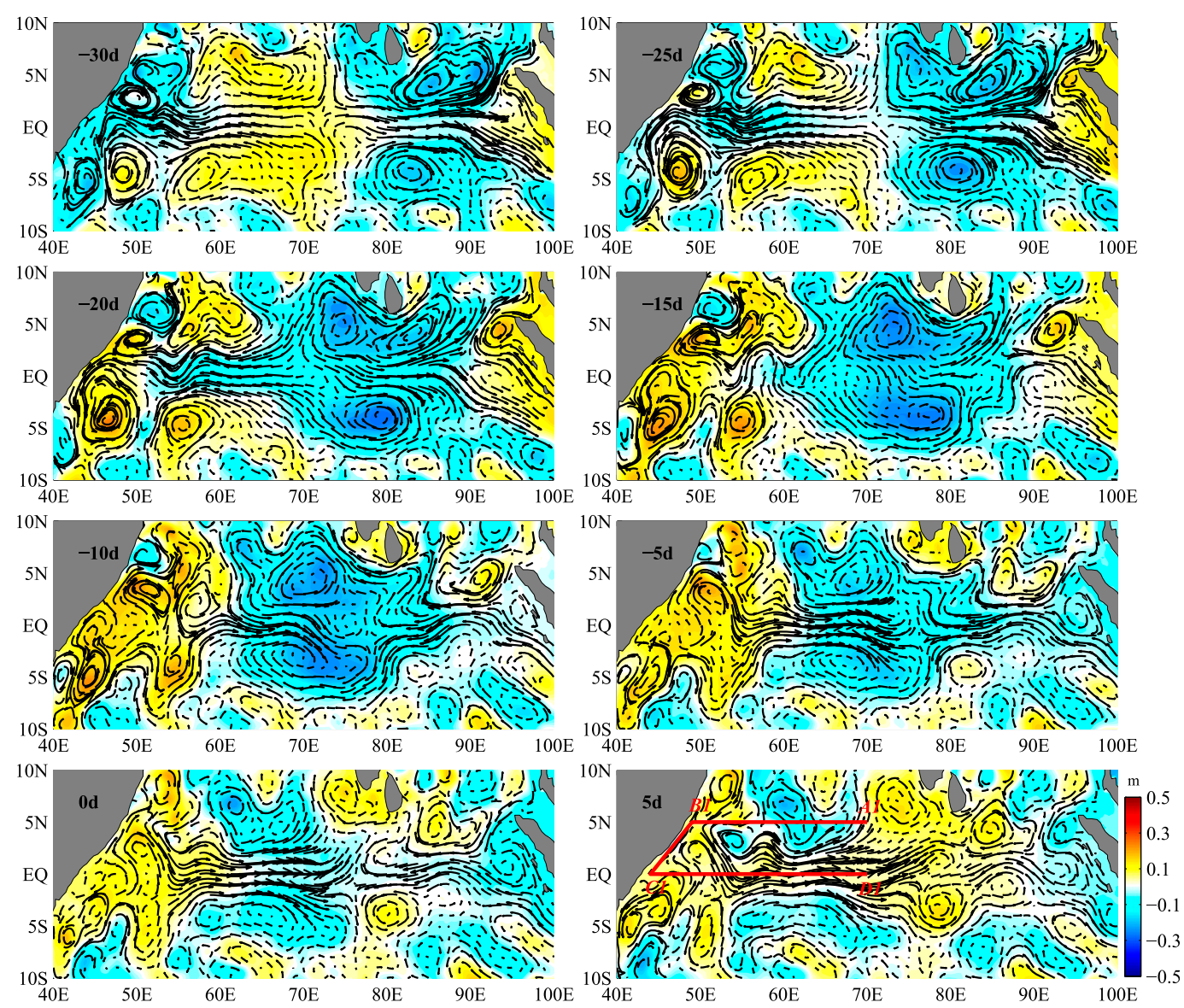

FIG. 12. Composite intraseasonal current anomaly averaged at $60-160 \mathrm{~m}$ (vectors) and SSHA of the strong $u$ events in the western basin (marked by circles in Fig. 4b). The red lines in the last subplot denote routes along $5^{\circ} \mathrm{N}$ (A1-B1), along the coasts of western boundary (B1-C1), and along the equator (C1-D1). Longitudes of A1-D1 are $70^{\circ}, 49^{\circ}, 44^{\circ}$, and $70^{\circ} \mathrm{E}$, respectively.

In the eastern basin, the STDs of intraseasonal velocity and transport anomalies at the subsurface layer are $0.08 \mathrm{~m} \mathrm{~s}^{-1}$ and $2.03 \mathrm{~Sv}$, respectively. The STD of the transport anomaly is approximately $66 \%$ of the STD of its climatological mean seasonal cycles of $3.60 \mathrm{~Sv}$ (Chen et al. 2016), demonstrating the indispensable role of ISV in the equatorial zonal water exchange. Compared to the eastern basin, the subsurface current and transport show weaker ISV in the western basin, with STDs of $0.06 \mathrm{~m} \mathrm{~s}^{-1}$ and $1.87 \mathrm{~Sv}$, respectively. To highlight the EUC ISV, we further examine velocity and transport during the EUC occurrence. STDs of velocity and transport are $0.08 \mathrm{~m} \mathrm{~s}^{-1}$ and $1.92 \mathrm{~Sv}$ in the western basin and $0.05 \mathrm{~m} \mathrm{~s}^{-1}$ and $1.77 \mathrm{~Sv}$ in the eastern basin, respectively.

Atmospheric ISOs (MR - NoISO) dominate ISV of currents at the subsurface layer in the eastern basin (89\%), whereas oceanic internal instabilities (NoISO) also contribute substantiality to ISV of currents in the western basin $(33 \%)$. However, when only the EUC-occurrence period is considered, the ratio of current anomalies from MR - NoISO, which measures atmospheric ISO impact, to HYCOM MR reaches $94 \%$ and $97 \%$ in the two basins. These results suggest the EUC ISV in the entire equatorial Indian Ocean is predominantly forced by atmospheric ISOs rather than induced by oceanic internal instabilities. Specifically, the effect of atmospheric ISOs on the EUC ISV is mainly through intraseasonal wind stress forcing (MR - NoSTRESS).

Intraseasonal wind stress induces equatorial Kelvin and Rossby waves. Rossby waves, reflected from the eastern boundary upon Kelvin waves' arrival, dominate the EUC ISV in the eastern basin during the early stage of the ISV. The eastward pressure gradient, which is set up after the radiation of the directly forced Kelvin and Rossby waves, as well as reflected Rossby waves, plays an important role during the peak of the EUC ISV. It takes 20-30 days to set up the intraseasonal current anomaly because of a mixed behavior of the first and 

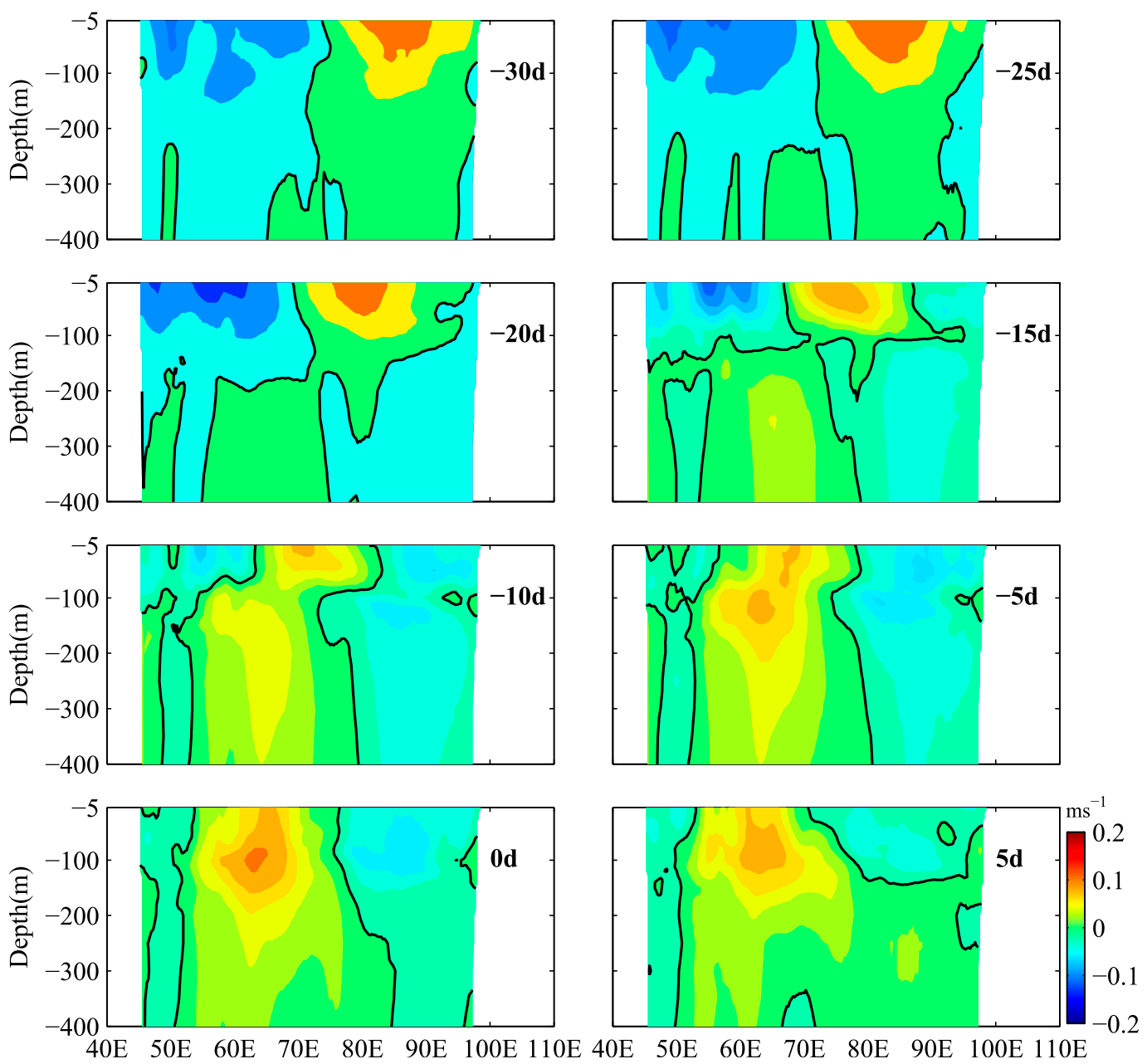

FIG. 13. Composite intraseasonal $u$ anomaly section averaged at $2^{\circ} \mathrm{S}-2^{\circ} \mathrm{N}$ of the strong $u$ events in the western basin (marked by circles in Fig. 4b).

second baroclinic modes. The EUC ISV is forced by wind stress with periods of 30-60 days, which is the primary spectral peak over the equator. Different from the situation in the eastern basin, the eastward pressure gradient forced over the western basin, which is set up by the westward-propagating Rossby waves driven by the easterly wind anomaly in the western basin and western boundary eddies, generates the EUC ISV in the western basin. The directly forced Rossby waves in the eastern basin propagate westward and remain considerable in magnitude in the western basin, which also contributes to the ISV of near-surface currents but appears to have little impact on the peak ISV of the EUC (Fig. 9).

The dominant intraseasonal zonal currents, with periods of 90 days through the resonant excitation, should have less impact on the EUC ISV in the eastern basin but contribute to the EUC ISV in the western basin, since it shifts westward to the western basin at the subsurface layer (Han 2005). The power spectra of the EUC averaged over $23.5-25.5 \mathrm{~kg} \mathrm{~m}^{-3}, 2^{\circ} \mathrm{S}-2^{\circ} \mathrm{N}$, and $80^{\circ}-90^{\circ} \mathrm{E}$ in the eastern basin show significant peaks at 33-69 days, but no peak at 90 days over the intraseasonal period (Fig. S1 in the online supplemental material). Compared to the eastern basin, the spectral power of the EUC at intraseasonal periods in the western basin $\left(60^{\circ}-70^{\circ} \mathrm{E}\right)$ is more evenly distributed and has an important peak at 90 days. Further quantitative examination, however, is required in order to prove this assertion. Since the IOD and El Niño-Southern Oscillation (ENSO) have significant influence on interannual variability and the EUC (e.g., Chen et al. 2015a), and the IOD also modulates atmospheric ISOs (Shinoda and Han 2005), they may also affect intraseasonal variability of the EUC. How they influence intraseasonal EUC, however, remains unclear, and it will be a good topic for future research. 
Acknowledgments. RAMA data were obtained at https://www.pmel.noaa.gov/gtmba/pmel-theme/indianocean-rama, the OLR data at http://www.esrl.noaa.gov/ psd/data/gridded/data.olrcdr.interp.html, and the CCMP data at $\mathrm{ftp} / / \mathrm{ftp} 2$. remss.com/ccmp/v02.0/. This work is supported by National Key R\&D Program of China (2017YFC1405103), XDA 20060502, NSFC 41822602, NSFC 41676010, State Key Laboratory of Tropical Oceanography SCSIO (LTOZZ1702), and Youth Innovation Promotion Association CAS (2017397), Guangzhou Science and Technology Foundation (201804010133).

\section{REFERENCES}

Atlas, R., J. Ardizzone, and R. N. Hoffman, 2008: Application of satellite surface wind data to ocean wind analysis. Proc. SPIE, 7087, 70870B, https://doi.org/10.1117/12.795371.

Bruce, J., 1973: Equatorial undercurrent in the western Indian Ocean during the southwest monsoon. J. Geophys. Res., 78, 6386-6394, https://doi.org/10.1029/JC078i027p06386.

Chen, G. X., W. Q. Han, Y. L. Li, D. X. Wang, and M. J. McPhaden, 2015a: Seasonal-to-interannual time-scale dynamics of the equatorial undercurrent in the Indian Ocean. J. Phys. Oceanogr., 45, 1532-1553, https://doi.org/10.1175/ JPO-D-14-0225.1.

$-,-\longrightarrow,-$, and T. Shinoda, 2015b: Intraseasonal variability of upwelling in the equatorial eastern Indian Ocean. J. Geophys. Res. Oceans, 120, 7598-7615, https://doi.org/10.1002/ 2015JC011223.

$-, \ldots,-$, and $\_, 2016$ : Interannual variability of equatorial eastern Indian Ocean upwelling: Local versus remote forcing. J. Phys. Oceanogr., 46, 789-807, https://doi.org/ 10.1175/JPO-D-15-0117.1.

,,--- M. J. McPhaden, J. Chen, W. Wang, and D. X. Wang, 2017: Strong intraseasonal variability of meridional currents near $5^{\circ} \mathrm{N}$ in the eastern Indian Ocean: Characteristics and causes. J. Phys. Oceanogr., 47, 979-998, https:// doi.org/10.1175/JPO-D-16-0250.1.

Dee, D. P., and Coauthors, 2011: The ERA-Interim reanalysis: Configuration and performance of the data assimilation system. Quart. J. Roy. Meteor. Soc., 137, 553-597, https://doi.org/ 10.1002/qj.828.

Han, W. Q., 2005: Origins and dynamics of the 90-day and 30-60-day variations in the equatorial Indian Ocean. J. Phys. Oceanogr., 35, 708-728, https://doi.org/10.1175/JPO2725.1.

— J. P. McCreary, D. L. T. Anderson, and A. J. Mariano, 1999: Dynamics of the eastern surface jets in the equatorial Indian Ocean. J. Phys. Oceanogr., 29, 2191-2209, https://doi.org/ 10.1175/1520-0485(1999)029<2191:DOTESJ > 2.0.CO;2

— D. M. Lawrence, and P. J. Webster, 2001: Dynamical response of equatorial Indian Ocean to intraseasonal winds: Zonal flow. Geophys. Res. Lett., 28, 4215-4218, https://doi.org/ 10.1029/2001GL013701.

Iskandar, I., Y. Masumoto, and K. Mizuno, 2009: Subsurface equatorial zonal current in the eastern Indian Ocean. J. Geophys. Res., 114, C06005, https://doi.org/10.1029/ 2008JC005188.

Kindle, J. C., and J. D. Thompson, 1989: The 26- and 50-day oscillations in the western Indian Ocean: Model results.
J. Geophys. Res., 94, 4721-4736, https://doi.org/10.1029/ JC094iC04p04721.

Knauss, J. A., and B. A. Taft, 1964: Equatorial undercurrent of the Indian Ocean. Science, 143, 354-356, https://doi.org/10.1126/ science.143.3604.354.

Knox, R., 1976: On a long series of measurements of Indian Ocean equatorial currents near Addu Atoll. Deep-Sea Res. Oceanogr. Abstr., 23, 211-221, https://doi.org/10.1016/ 0011-7471(76)91325-5.

Kummerow, C., W. Barnes, T. Kozu, J. Shiue, and J. Simpson, 1998 : The Tropical Rainfall Measuring Mission (TRMM) sensor package. J. Atmos. Oceanic Technol., 15, 809-817, https://doi.org/ 10.1175/1520-0426(1998)015<0809:TTRMMT>2.0.CO;2.

Li, Y., W. Han, T. Shinoda, C. Wang, R. C. Lien, J. N. Moum, and J. W. Wang, 2013: Effects of the diurnal cycle in solar radiation on the tropical Indian Ocean mixed layer variability during wintertime Madden-Julian oscillations. J. Geophys. Res. Oceans, 118, 4945-4964, https://doi.org/10.1002/jgrc.20395.

,,,,---- M. Ravichandran, and J. W. Wang, 2014 Revisiting the wintertime intraseasonal SST variability in the tropical South Indian Ocean: Impact of the ocean interannual variation. J. Phys. Oceanogr., 44, 1886-1907, https://doi.org/ 10.1175/JPO-D-13-0238.1.

$\longrightarrow,-$ and T. Lee, 2015: Intraseasonal sea surface salinity variability in the equatorial Indo-Pacific Ocean induced by Madden-Julian oscillations. J. Geophys. Res. Oceans, 120, 2233-2258, https://doi.org/10.1002/2014JC010647.

W. Wang, M. Ravichandran, T. Lee, and T. Shinoda, 2017: Bay of Bengal salinity stratification and Indian summer monsoon intraseasonal oscillation: 2. Impact on SST and convection. J. Geophys. Res. Oceans, 122, 4312-4328, https:// doi.org/10.1002/2017JC012692.

Liebmann, B., and C. A. Smith, 1996: Description of a complete (interpolated) outgoing longwave radiation dataset. Bull. Amer. Meteor. Soc., 77, 1275-1277, https://doi.org/10.1175/ 1520-0477-77.6.1274.

Luyten, J. R., and D. H. Roemmich, 1982: Equatorial currents at semi-annual period in the Indian Ocean. J. Phys. Oceanogr., 12, 406-413, https://doi.org/10.1175/1520-0485(1982)012<0406: ECASAP $>2.0 . \mathrm{CO} ; 2$.

Masumoto, Y., H. Hase, Y. Kuroda, H. Matsuura, and K. Takeuchi, 2005: Intraseasonal variability in the upper layer currents observed in the eastern equatorial Indian Ocean. Geophys Res. Lett., 32, L02607, https://doi.org/10.1029/2004GL021896.

McPhaden, M. J., 1982: Variability in the central equatorial Indian Ocean. I: Ocean dynamics. J. Mar. Res., 40, 157-176.

— , and Coauthors, 2009: RAMA: The Research Moored Array for African-Asian-Australian Monsoon Analysis and Prediction. Bull. Amer. Meteor. Soc., 90, 459-480, https://doi.org/ 10.1175/2008BAMS2608.1.

Moore, D. W., and J. P. McCreary, 1990: Excitation of intermediate-frequency equatorial waves at a western ocean boundary: With application to observations from the Indian Ocean. J. Geophys. Res., 95, 5219-5231, https://doi.org/ 10.1029/JC095iC04p05219.

Murty, V. S. N., and Coauthors, 2002: First results of Indian current meter moorings along the equator: Vertical current structure variability at equator, $93^{\circ} \mathrm{E}$ during February-December 2000. Proc. Sixth Pan Ocean Remote Sensing Conf., Bali, Indonesia, Scientific Organizing Committee of PORSEC, 25-28, http:// drs.nio.org/drs/handle/2264/1406.

Nagura, M., and M. J. McPhaden, 2010: Dynamics of zonal current variations associated with the Indian Ocean dipole. 
J. Geophys. Res., 115, C11026, https://doi.org/10.1029/ 2010JC006423.

Nyadjro, E., and M. J. McPhaden, 2014: Variability of zonal currents in the eastern equatorial Indian Ocean on seasonal to interannual time scales. J. Geophys. Res. Oceans, 119, 7969-7986, https://doi.org/10.1002/2014JC010380.

Ren, Q., Y. Li, F. Wang, L. Song, C. Liu, and F. Zhai, 2018: Seasonality of the Mindanao Current/Undercurrent system. J. Geophys. Res. Oceans, 123, 1105-1122, https://doi.org/ 10.1002/2017JC013474.

Reppin, J., F. A. Schott, J. Fischer, and D. Quadfasel, 1999: Equatorial currents and transports in the upper central Indian Ocean: Annual cycle and interannual variability. J. Geophys. Res., 104, 15 495-15 514, https://doi.org/10.1029/ 1999JC900093.

Schott, F. A., and J. P. McCreary, 2001: The monsoon circulation of the Indian Ocean. Prog. Oceanogr., 51, 1-123, https://doi.org/ 10.1016/S0079-6611(01)00083-0.

Senan, R., D. Sengupta, and B. N. Goswami, 2003: Intraseasonal "monsoon jets" in the equatorial Indian Ocean. Geophys. Res. Lett., 30, 1750, https://doi.org/10.1029/ 2003 GL017583.

Sengupta, D., R. Senan, and B. N. Goswami, 2001: Origin of intraseasonal variability of circulation in the tropical central Indian Ocean. Geophys. Res. Lett., 28, 1267-1270, https://doi.org/10.1029/2000GL012251.

,,$-- \ldots$, and J. Vialard, 2007: Intraseasonal variability of equatorial Indian Ocean zonal currents. J. Climate, 20, 3036-3055, https://doi.org/10.1175/JCLI4166.1.
Shankar, D., J. McCreary, W. Han, and S. Shetye, 1996: Dynamics of the East India Coastal Current: 1. Analytic solutions forced by interior Ekman pumping and local alongshore winds. J. Geophys. Res., 101, 13 975-13 991, https://doi.org/10.1029/96JC00559.

Shinoda, T., and W. Han, 2005: Influence of Indian Ocean dipole on atmospheric subseasonal variability. J. Climate, 18, 3891-3909, https://doi.org/10.1175/JCLI3510.1.

- - L. Zamudio, R.-C. Lien, and M. Katsumata, 2017: Remote ocean response to the Madden-Julian oscillation during the DYNAMO field campaign: Impact on Somali Current system and Seychelles-Chagos thermocline ridge. Atmosphere, 8, 171, https://doi.org/10.3390/atmos8090171.

Swapna, P., and R. Krishnan, 2008: Equatorial undercurrents associated with Indian Ocean dipole events during contrasting summer monsoons. Geophys. Res. Lett., 35, L14S04, https:// doi.org/10.1029/2008GL033430.

Wallcraft, A., E. Metzger, and S. Carroll, 2009: Software design description for the Hybrid Coordinate Ocean Model (HYCOM), version 2.2. Naval Research Lab Tech. Memo., 157 pp., https://apps.dtic.mil/dtic/tr/fulltext/u2/a494779.pdf.

Wielicki, B. A., B. R. Barkstrom, E. F. Harrison, R. B. Lee, G. L. Smith, and J. E. Cooper, 1996: Clouds and the Earth's Radiant Energy System (CERES): An Earth Observing System experiment. Bull. Amer. Meteor. Soc., 77, 853-868, https://doi.org/ 10.1175/1520-0477(1996)077<0853:CATERE >2.0.CO;2.

Woodberry, K. E., M. E. Luther, and J. J. O'Brien, 1989: The winddriven seasonal circulation in the southern tropical Indian Ocean. J. Geophys. Res., 94, 17 985-18 002, https://doi.org/ 10.1029/JC094iC12p17985. 